\title{
DFT analysis of the nucleophilicity of substituted pyridines and prediction of new molecules having nucleophilic character stronger than 4-pyrrolidino pyridine
}

\author{
KAUSTAVMONI DEKA and PRODEEP PHUKAN* \\ Department of Chemistry, Gauhati University, Guwahati 781 014, Assam, India \\ e-mail:pphukan@yahoo.com
}

MS received 22 September 2015; revised 26 January 2016; accepted 1 February 2016

\begin{abstract}
Some commonly used 3-substituted, 4-substituted and 3,4,5-substituted pyridines were examined using DFT to predict the nucleophilicity behavior based on four different methods known in the literature. HOMO-LUMO energy calculations were done using DFT/B3LYP/6-311G+(d,p) level of theory. To establish the most suitable nucleophilicity scale for all the ranges of pyridines covered herein, either Hammett substituent constant $(\sigma)$ or experimental nucleophilicity values were computed. On the basis of this study, some new 4 -substituted pyridines with enhanced nucleophilicity have been proposed. Nucleophilic behaviour of a few predicted molecules was found to be better than that of 4-pyrrolidino pyridine.
\end{abstract}

Keywords. Density functional theory; nucleophilicity; organo-catalyst; pyridine.

\section{Introduction}

Since the early twentieth century, pyridine derivatives have found widespread applications as commercially important substrate. Pyridine was first synthesized in 1876. ${ }^{1}$ Pyridine derivatives find applications in a variety of areas such as bioactive compounds, ${ }^{2,3}$ insecticides, ${ }^{4}$ fungicides, ${ }^{5}$ plant growth regulators ${ }^{6-8}$ and most extensively used as organocatalysis. ${ }^{9-12}$ Organocatalysts have received enormous attention due to their advantages such as inertness towards moisture and oxygen, easy reaction conditions, absence of transition metals, etc. ${ }^{13,14}$ In the recent past, there has been a significant progress in the development of more active pyridine based organocatalysts for various organic transformations. ${ }^{15}$ The activity of the organocatalysts largely depends on their nucleophilic character. ${ }^{16}$ The concept of nucleophile and electrophile ${ }^{17}$ leads to the development of nucleophilicity/electrophilicity scale.

Initially, nucleophilicity trends were established on the basis of certain experimental parameters. To determine nucleophilicity quantitatively, Swain and Scott ${ }^{18}$ introduced the first nucleophilicity scale based on linear free energy relationship as

$$
\log \left(\mathrm{k} / \mathrm{k}_{0}\right)=\mathrm{s} \mathrm{n}
$$

where $\mathrm{k}$ is the rate constant for the $\mathrm{S}_{\mathrm{N}} 2$ reaction of a substrate with a particular nucleophile, $\mathrm{k}_{0}$ is the corresponding rate constant with reference nucleophile

\footnotetext{
*For correspondence
}

(water), $\mathrm{n}$ is the intrinsic nucleophilicity for a particular substrate and $\mathrm{s}$ is the sensitivity parameter of the substrate.

Later, Edwards ${ }^{19,20}$ proposed a more general equation incorporating basicity, polarizability and oxidation potential to estimate nucleophilicy parameter. Bunnet ${ }^{21}$ suggested that several factors that must be considered in order to quantitatively describe the nucleophilicity. Pearson $^{22}$ explained that the principle of hard and soft acids and bases (HSAB) can also be applied for determination of nucleophilicity. Legon and Millen used hydrogen bonding as a probe for electron density while determining the nucleophilicity and electrophilicity of hydrogen bonded complexes from rotational spectra. $^{23,24}$ This study was carried out specifically for hydrogen bonded dimers of the type B-HX where B is a Lewis base and HX is a molecule of electrophilic character.

Mayr and coworkers successfully developed an experimental nucleophilic scale for several 4-substituted pyridine $^{25}$ and 3,4,5-substituted pyridine. ${ }^{26}$ They measured the rate of the reactions of corresponding substituted pyridines with benzhydrylium ions using a new linear free energy relationship

$$
\log \mathrm{k}=\mathrm{s}(\mathrm{E}+\mathrm{N})
$$

where electrophiles were characterized by the parameter $\mathrm{E}$ and nucleophiles were characterized by two parameters ( $\mathrm{N}$ and $\mathrm{s})$. The authors proved that this equation is sufficient to describe quantitatively the reaction rate 
of a large variety of electrophile-nucleophile combinations. To understand the mechanistic aspects such as intermolecular selectivity, intramolecular selectivity, solvation effect, etc., of chemical reactions, theoretical scales of nucleophilicity/electrophilicity ${ }^{27,28}$ are very much desirable and helpful to experimental chemist.

Inverse relationship ${ }^{29}$ between electrophilicity and nucleophilicity was first proposed and validate in the study of helium atom interactions with strong laser pulses. The study revealed that a particular molecular site may undergo more likely an electrophilic attack or another site undergoes nucleophilic attack. Recently, Roy et al., developed a theoretical nucleophilicity scale for some commonly used arenes and heteroarenes ${ }^{30}$ by using the inverse concept of electrophilicity and nucleophilicity. In their publication, nucleophilicity values were determined using four different available theoretical methods in literature and tested linearity between Hammett substituent constant to judge the goodness of the methods. Subsequently, they determined the nucleophilicity of organotin and allyl metal reagents ${ }^{31}$ by applying the best methods which were evaluated in their earlier publication. ${ }^{30}$ Domingo et al. ${ }^{32}$ recently verified the inverse of the electrophilicity and the inverse of the electron donating power proposed by Roy et al., for 5-substituted indoles, para-substituted phenols and 2,5-disubstituted bicyclic[2.2.1] hepta-2,5-dienes.

To develop a theoretical nucleophilicity scale for substituted pyridine, attempts have been made for very few pyridines based on the intermolecular stretching force constant of H-bonded complexes and molecular electrostatic potential. ${ }^{33}$ Recently, we made an effort for a theoretical evaluation of nucleophilicity values of few nitrogen nucleophiles along with six numbers of 4 -substituted pyridine analogues. ${ }^{34}$ Soliman also made an effort to determine the reactivity of some substituted pyridine ligands as nucleophile towards $\mathrm{H}^{+}$, $\mathrm{Cu}^{+}$and $\mathrm{Cu}^{2+}$ Lewis acids as electrophile. ${ }^{35}$ So far no elaborate study has been made for a theoretical correlation of nucleophilicity behavior of various substituted pyridines.

Within the context of density functional theory, ${ }^{36,37}$ many global and local reactivity descriptors have been defined. Global and local reactivity descriptors are widely used to study the reactivity and selectivity of chemical species. A series of reviews has been published by Chattaraj regarding different reactivity descriptors such as chemical potential $(\mu)$, chemical hardness $(\eta)$, softness $(\mathrm{S})$ and electrophilicity index

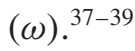

In this study, the earlier reported four methods for prediction of nucleophilicity were applied and tested for 3-substituted, 4-substituted, and 3,4,5-substituted pyridine in order to evaluate the suitability of method for each category of substituted pyridines. Based on our analysis, we made an effort to predict some new 4-substituted pyridine analogues with enhanced nucleophilicity values.

\section{Computational Methods}

One of the important global reactivity descriptor hardness $\eta$ is defined as, ${ }^{40}$

$$
\eta \approx(\mathrm{I}-\mathrm{A})
$$

Where I and A are the vertical ionization energy and electron affinity. Softness (S) is the reciprocal of hardness and defined as,

$$
\mathrm{S}=\frac{1}{\eta}=\frac{1}{I-A}
$$

Global electrophilicity index introduced by Parr et al., ${ }^{40,41}$ is expressed as,

$$
\omega=\frac{\mu^{2}}{2 \eta}
$$

Where $\mu$ is the electronic chemical potential ${ }^{42}$ defined as,

$$
\mu=\frac{-(I+A)}{2}
$$

Using Koopman's theorem, ionization energy (I) and electron affinity (A) can be replaced by the frontier molecular energies of HOMO $\left(\mathrm{E}_{\mathrm{H}}\right)$ and LUMO $\left(\mathrm{E}_{\mathrm{L}}\right)$ respectively. Therefore $\mu$ and $\eta$ can be expressed as,

$$
\eta=\mathrm{E}_{\mathrm{L}}-\mathrm{E}_{\mathrm{H}} \text { and } \mu=\frac{E_{L}+E_{H}}{2}
$$

In an important contribution, Gazquez et al., ${ }^{43}$ have defined electron donating power $\omega^{-}$as,

$$
\omega^{-}=\frac{I^{2}}{2(I-A)}
$$

and

$$
\omega^{-}=\frac{(3 l+A)^{2}}{16(I-A)}
$$

Domingo et al. ${ }^{44}$ proposed the simplest approach relating the nucleophilicity $\mathrm{N}$ with the highest occupied molecular orbital (HOMO) energy within the KohnSham Scheme ${ }^{45}$ as,

$$
\mathrm{N}=\mathrm{E}_{\text {Номо }}-\mathrm{E}_{\text {Номо(тСЕ) }} \mathrm{eV}
$$

Where tetracyanoethylene (TCE) was taken as a reference. In this scale, the nucleophilicity index for TCE 
is $\mathrm{N}=0.0 \mathrm{eV}$, presenting the lowest HOMO energy in a long series of organic molecules was already considered.

In order to rationalize with the general notion that "more is better" Roy et al., ${ }^{30}$ proposed the nucleophilicity index $\mathrm{N}^{\prime \prime}$, as the inverse of electron donating $\left(\omega^{-}\right)$ power. ${ }^{43}$ Since the nucleophilicity index obtained as $\frac{1}{\omega^{-}}$ was below 1 , the author defined the nucleophilicity $\mathrm{N}^{\prime \prime}$ $\& \mathrm{~N}^{\prime \prime \prime}$ as $^{31}$

$$
\mathrm{N}^{\prime \prime}=\frac{1}{\omega^{-}} \times 10 \text { and } \mathrm{N}^{\prime \prime \prime}=\frac{1}{\omega^{-}} \times 10
$$

Following methods ${ }^{30}$ were adopted for the present study.

$$
\begin{aligned}
& \mathrm{N}=\mathrm{E}_{\text {Номо }}-\mathrm{E}_{\text {Номо(тсе) }} \mathrm{eV} \\
& \mathrm{N}^{\prime}=\frac{1}{\omega} \quad \text { where } \omega=\frac{\mu^{2}}{2 \eta} \\
& \mathrm{N}^{\prime \prime}=\frac{1}{\omega^{-}} \quad \text { where } \omega^{-}=\frac{I^{2}}{2(I-A)} \\
& \mathrm{N}^{\prime \prime \prime}=\frac{1}{\omega^{-}} \quad \text { where } \omega^{-}=\frac{(3 I+A)^{2}}{16(I-A)} \\
& \text { (12) Method III } \\
& \text { (13) Method IV }
\end{aligned}
$$

Geometries of all the molecules were first optimized using density functional three-parameter hybrid model (DFT/B3LYP). ${ }^{46-48}$ The basis set for optimization is 6-31G(d,p). Single point energies were calculated on optimized geometries using DFT/B3LYP/6-311G+(d,p) level of theory to obtain the HOMO-LUMO energies in gas phase and solvent phase. For solvent phase calculation, polarizable continuum model was applied using the integral equation formalism variant (IEFPCM). All calculations were carried out using Gaussian03 Revision E.01 programme. ${ }^{49}$

\section{Results and Discussion}

Since experimental nucleophilicity values of a few 4-substituted pyridines are known in the literature, ${ }^{25}$ initial study was carried out by taking examples of 4substituted pyridines. Mayr has already determined the nucleophilicity values of six 4-substituted pyridines in dichloromethane. To verify the applicability of these theoritical methods, nucleophilicity indexs $\mathrm{N}, \mathrm{N}^{\prime}, \mathrm{N}^{\prime \prime}$ and $\mathrm{N}^{\prime \prime \prime}$ were calculated in the gas phase based on the four methods I, II, III and IV, respectively, for all the 4-substituted pyridines for which the experimental nucleophilicity values were reported by Mayr. ${ }^{25}$ The calculated values are listed in table 1 . Leave one out cross validation and regression analysis by distributing the molecules in training and test sets indicated the validity of the methods (see Supplementary Information).

Calculated gas phase global nucleophilicity values determined by the method I, II, III and IV were plotted against Mayr's experimental nucleophilicity values (figure 1).

The regression coefficients $\left(\mathrm{R}^{2}\right)$ for Method I, II, III and IV are found to be 0.926, 0.930, 0.927 and 0.931 , respectively. This result indicated that all the four methods generate similar correlation. It is well known that solvent plays an important role in nature for reg-

\begin{tabular}{|c|c|c|c|c|c|c|c|c|c|c|}
\hline \multirow[b]{2}{*}{ Entry } & \multirow[b]{2}{*}{ Compound } & \multicolumn{2}{|c|}{$\mathrm{N}$} & \multicolumn{2}{|c|}{$\mathrm{N}^{\prime}$} & \multicolumn{2}{|c|}{$\mathrm{N}^{\prime \prime}$} & \multicolumn{2}{|c|}{$\mathrm{N}^{\prime \prime \prime}$} & \multirow{2}{*}{$\begin{array}{c}\mathrm{N} \\
\text { Expt. }^{\mathrm{a}}\end{array}$} \\
\hline & & Gas & Solvent & Gas & Solvent & Gas & Solvent & Gas & Solvent & \\
\hline 1 & 4-chloropyridine & 1.85 & 1.36 & 0.60 & 0.61 & 2.13 & 2.13 & 1.67 & 1.69 & 11.70 \\
\hline 2 & 4-methylpyridine & 2.31 & 1.69 & 0.74 & 0.72 & 2.41 & 2.34 & 1.95 & 1.90 & 13.70 \\
\hline 3 & 4-methoxy pyridine & 2.42 & 1.94 & 0.83 & 0.80 & 2.54 & 2.49 & 2.10 & 2.05 & 13.70 \\
\hline 4 & 4-aminopyridine & 2.95 & 2.64 & 0.94 & 0.95 & 2.79 & 2.83 & 2.34 & 2.37 & 15.20 \\
\hline 5 & 4-(N,N-dimethylamino) pyridine & 3.50 & 3.07 & 1.10 & 1.02 & 3.13 & 3.04 & 2.67 & 2.55 & 15.70 \\
\hline 6 & 4-(pyrrolidino) pyridine & 3.63 & 3.21 & 1.15 & 1.06 & 3.23 & 3.13 & 2.76 & 2.63 & 15.90 \\
\hline
\end{tabular}
ulating the extent of interaction energy and reactivity

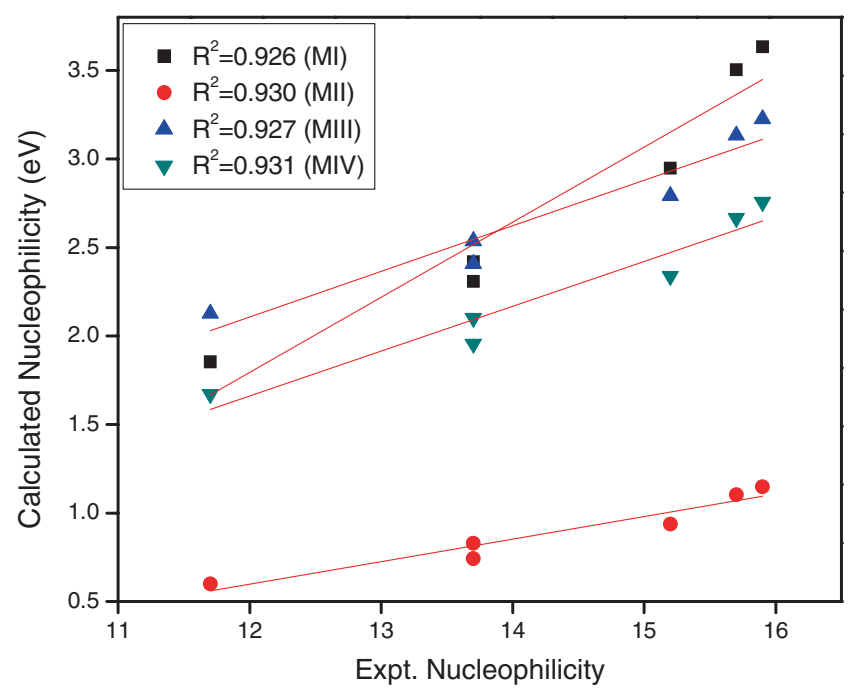

Figure 1. Gas phase nucleophilicity vs experimental nucleophilicity for 4-substituted pyridines.

Table 1. Calculated gas and solvent phase global nucleophilicity (eV) and Mayr's experimental values for six 4-substituted pyridines.

${ }^{\mathrm{a}}$ Experimental values are taken from the literature ${ }^{25}$; Solvent=dichloromethane 
amongst the molecule. ${ }^{50-52}$ Since, experimental nucleophilicity values were obtained in dichloromethane, the global nucleophilicity parameters for all the six pyridines were calculated using the IEFPCM solvent model for dichloromethane (DCM) solution. The Calculated values are summarized in table 1 .

The calculated solvent phase nucleophilicity values obtained by using the four methods were plotted against the experimental nucleophilicity values in the DCM solution (figure 2).

The $\mathrm{R}^{2}$ values obtained for methods I, II, III and IV are found to be $0.919,0.950,0.933$ and 0.943 , respectively. Regression coefficients obtained from the above study indicate that inclusion of solvent model gives better correlation for method II, III and IV than gas phase calculation. For the method $\mathrm{I}$, the $\mathrm{R}^{2}$ value for solvent

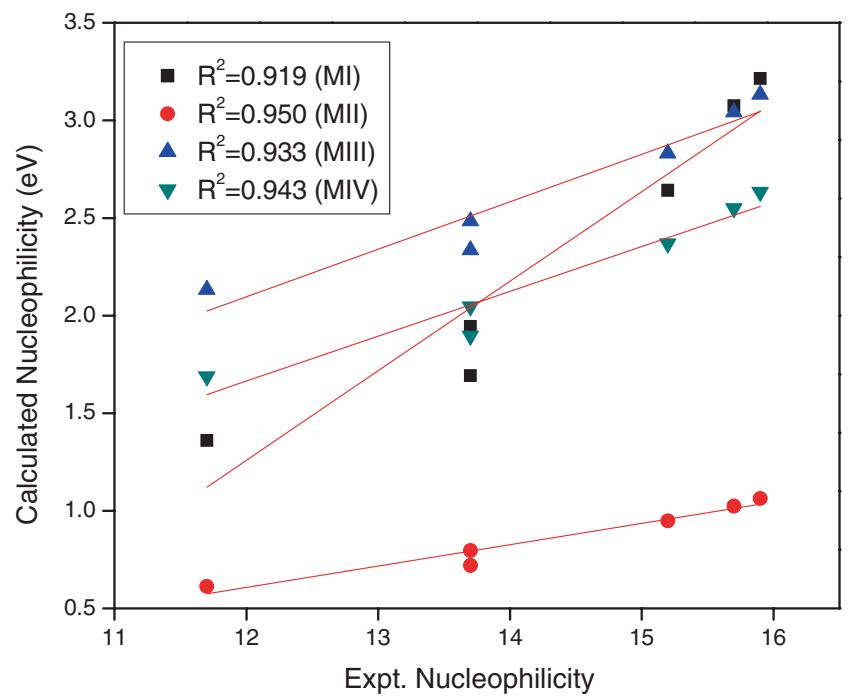

Figure 2. Calculated nucleophilicity in IEFPCM solvent model vs. expt. nucleophilicity for 4-substituted pyridines. model decreases compared to gas phase calculation. However, these differences are negligible because of little difference in the nucleophilicity trends in gas phase and solvent phase calculation.

To verify the methods further, twelve commercially available 4-substituted pyridines for which Hammett substituent constant are known, ${ }^{53}$ were chosen for nucleophilicity study. It has already been reported that the Hammett substituent constant can be taken as a standard for verification of the validity of the methods. ${ }^{30,31}$ The gas phase global nucleophilicity were calculated using methods I, II, III and IV. A comparison of gas phase global nucleophilicity values with Hammett substituted constant $(\sigma)$ values were summarized in table 2 .

Further, the calculated gas phase global nucleophilicity values were plotted against the Hammett

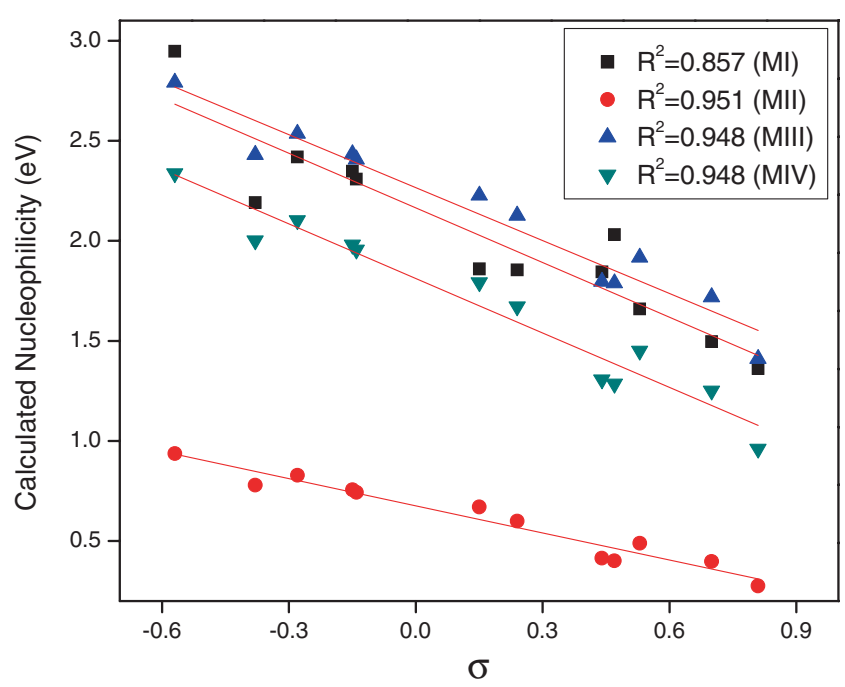

Figure 3. Gas phase Nucleophilicity vs. Hammett substituent constant $(\sigma)$ for 4 -substituted pyridines.

Table 2. Gas phase global nucleophilicity values for twelve 4-substituted pyridine and Hammett substituent constant $^{53}(\sigma)$ values.

\begin{tabular}{|c|c|c|c|c|c|c|}
\hline Entry & Compound & $\mathrm{N}$ & $\mathrm{N}^{\prime}$ & $\mathrm{N}^{\prime \prime}$ & $\mathrm{N}^{\prime \prime \prime}$ & $\sigma$ \\
\hline 1 & 4-fluoropyridine & 1.86 & 0.67 & 2.23 & 1.79 & 0.15 \\
\hline 2 & 4-chloropyridine & 1.85 & 0.60 & 2.13 & 1.67 & 0.24 \\
\hline 3 & 4-nitropyridine & 1.36 & 0.28 & 1.41 & 0.96 & 0.81 \\
\hline 4 & 4-hydroxypyridine & 2.19 & 0.78 & 2.43 & 2.00 & -0.38 \\
\hline 5 & 4-aminopyridine & 2.95 & 0.94 & 2.79 & 2.34 & -0.57 \\
\hline 6 & 4-trifluoromethylpyridine & 1.66 & 0.49 & 1.92 & 1.45 & 0.53 \\
\hline 7 & 4-pyridinecarbonitrile & 1.50 & 0.40 & 1.72 & 1.25 & 0.70 \\
\hline 8 & 4-methylpyridine & 2.31 & 0.74 & 2.41 & 1.95 & -0.14 \\
\hline 9 & 4-methoxypyridine & 2.42 & 0.83 & 2.54 & 2.10 & -0.28 \\
\hline 10 & 4-acetylpyridine & 2.03 & 0.40 & 1.79 & 1.29 & 0.47 \\
\hline 11 & 4-tert-butylpyridine & 2.35 & 0.76 & 2.43 & 1.98 & -0.15 \\
\hline 12 & Isonicotinic acid & 1.84 & 0.41 & 1.80 & 1.31 & 0.44 \\
\hline
\end{tabular}


substituent constant (figure 3). For this case, the regression coefficients $\mathrm{R}^{2}$ for the methods I, II, III and IV are found to be $0.857,0.951,0.948$ and 0.948 , respectively.

In this case also, the methods II, III and IV could generate better correlation with good regression coefficient as compared to method I. After having success in getting good correlation for nucleophilicity values for these substrates, another set of 36 commonly used 4substituted pyridines were considered for predicting gas phase global nucleophilicity. Comparison of our theoretically calculated nucleophilicity values with the available experimental data revealed that the method II and IV are most successful with highest correlation value with experimental as well as Hammett substituent constant. Hence, method II and IV were applied for subsequent calculations of nucleophilicity values of these 36 numbers of 4-substituted pyridine analogues. Table 3 gives the nucleophilicity values applying both the methods.

Altogether, 50 numbers of 4-substituted pyridine nucleophiles were considered in this study. On the basis of gas phase global nucleophilicity value, the pyridines were arranged in such a way that the lowest nucleophilic pyridine is at the bottom of the scale (figure 4).

From this analysis, it can be concluded that 4pyrrolidino pyridine has the highest nucleophilicity

Table 3. Gas phase global nucleophilicity values (eV) 36 commonly used 4-substituted pyridines calculated by method II and method IV.

\begin{tabular}{|c|c|c|c|}
\hline Entry & Compound & N' & $\mathrm{N}^{\prime \prime \prime}$ \\
\hline 1 & 4-bromopyridine & 0.59 & 1.66 \\
\hline 2 & 4-pyridinecarboxaldehyde & 0.36 & 1.18 \\
\hline 3 & Isonicotinamide & 0.47 & 1.44 \\
\hline 4 & 4-ethylpyridine & 0.74 & 1.95 \\
\hline 5 & 4-(1-aminoethyl)pyridine & 0.75 & 1.99 \\
\hline 6 & 4-(1H-pyrazol-4-yl)pyridine & 0.63 & 1.79 \\
\hline 7 & 4-(2-aminoethyl)pyridine & 0.74 & 1.97 \\
\hline 8 & 4-(3-phenylpropyl) pyridine & 0.76 & 2.01 \\
\hline 9 & 4-(4-formylphenyl)pyridine & 0.38 & 1.24 \\
\hline 10 & 4-(aminomethyl)pyridine & 0.74 & 1.97 \\
\hline 11 & 4-(boc-amino)pyridine & 0.74 & 1.97 \\
\hline 12 & 4-(bromomethyl)pyridine & 0.50 & 1.49 \\
\hline 13 & 4-(chloromethyl)pyridine & 0.54 & 1.57 \\
\hline 14 & 4-(ethylaminomethyl) pyridine & 0.78 & 2.07 \\
\hline 15 & 4-benzylpyridine & 0.72 & 1.94 \\
\hline 16 & 4-isobutylpyridine & 0.74 & 1.95 \\
\hline 17 & 1-(pyridin-4-ylmethyl) piperidine-3-carboxylic acid & 0.77 & 2.07 \\
\hline 18 & (N,N-diethyl)-4-aminomethylpyridine & 0.82 & 2.19 \\
\hline 19 & 4-morpholinopyridine & 0.93 & 2.38 \\
\hline 20 & 4-phenylpyridine & 0.57 & 1.68 \\
\hline 21 & 4-pyridinemethanol & 0.74 & 1.95 \\
\hline 22 & 4-pyridinepropanol & 0.77 & 2.01 \\
\hline 23 & 4-pyridylacetic acid & 0.67 & 1.83 \\
\hline 24 & 4-pyridylacetonitrile & 0.58 & 1.64 \\
\hline 25 & (4-pyridylthio)acetic acid & 0.71 & 1.94 \\
\hline 26 & diphenyl-4-pyridylmethanol & 0.69 & 1.89 \\
\hline 27 & diphenyl-4-pyridylmethane & 0.72 & 1.95 \\
\hline 28 & Ethyl isonicotinate & 0.45 & 1.40 \\
\hline 29 & Isonicotinoyl chloride & 0.32 & 1.08 \\
\hline 30 & Ethyl 4-pyridylacetate & 0.67 & 1.83 \\
\hline 31 & Methyl isonicotinate & 0.45 & 1.38 \\
\hline 32 & Nialamide & 0.55 & 1.63 \\
\hline 33 & 1-(pyridine-4-yl)ethanol & 0.74 & 1.95 \\
\hline 34 & 1-(pyridin-4-ylmethyl) pyrrolidin-2-one & 0.68 & 1.88 \\
\hline 35 & 1-(pyridin-4-ylmethyl) piperidine-4-carboxylic acid & 0.75 & 2.03 \\
\hline 36 & 4-thionitrosopyridine & 0.14 & 0.59 \\
\hline
\end{tabular}




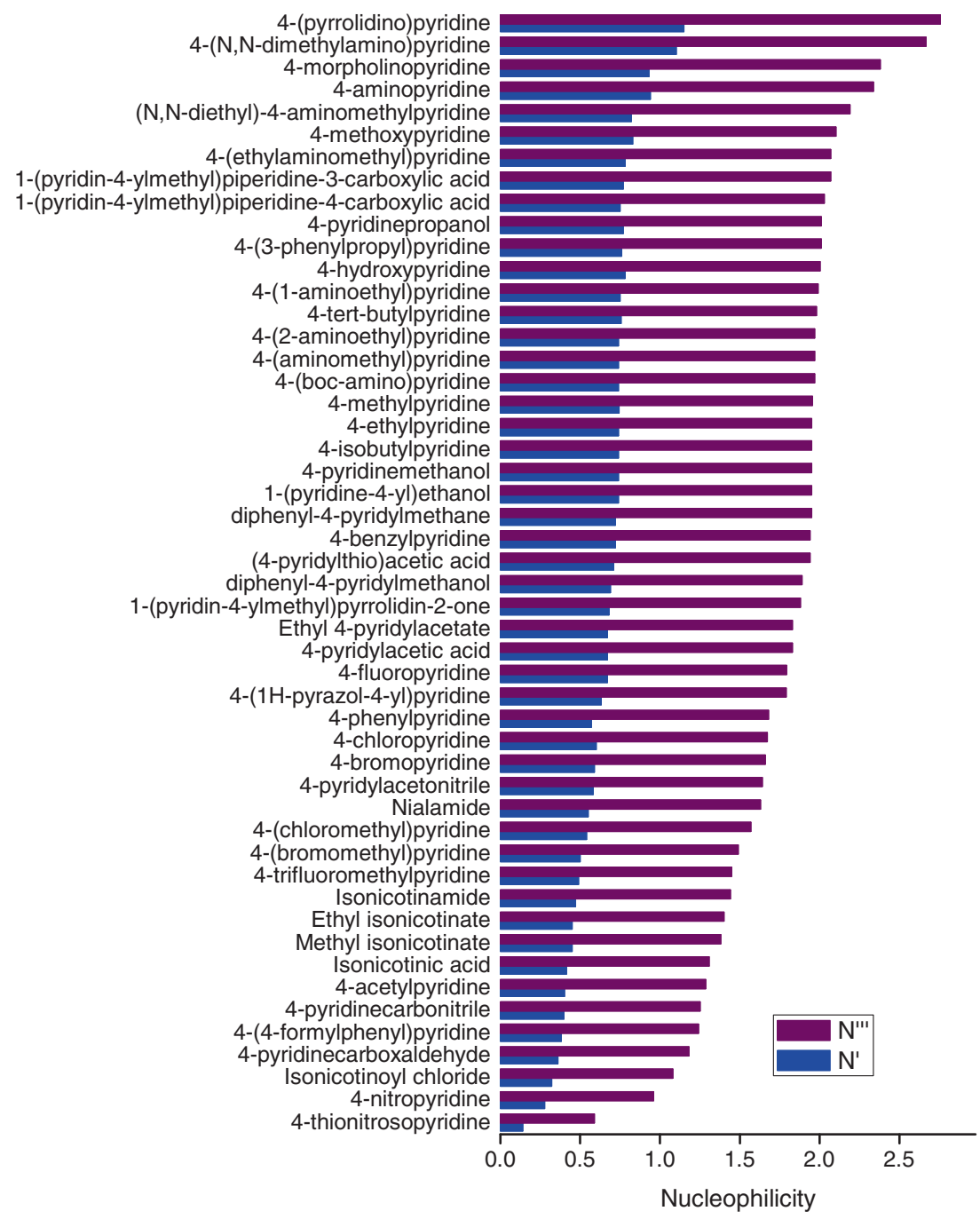

Figure 4. Nucleophilicity scale of 50 no. of 4-substituted pyridines based on gas phase calculation.

value among all 4-substituted pyridines. Both the experimental as well as theoretical methods placed it on the top of the scale in terms of nucleophilic behavior followed by 4-dimethylaminopyridine (DMAP). 4Morpholinopyridine and 4-aminopyridine have similar values of nucleophilicity as predicted by method II

Table 4. Gas phase global nucleophilicity values $(\mathrm{eV})$ of 12 no. of 3-substituted pyridines and Hammett substituent constant $^{53}(\sigma)$ values.

\begin{tabular}{lcccccc}
\hline Entry & Compound & $\mathrm{N}$ & $\mathrm{N}^{\prime}$ & $\mathrm{N}^{\prime \prime}$ & $\mathrm{N}^{\prime \prime \prime}$ & $\sigma$ \\
\hline 1 & 3-fluoropyridine & 1.96 & 0.60 & 2.14 & 1.68 & 0.34 \\
2 & 3-chloropyridine & 2.07 & 0.59 & 2.15 & 1.68 & 0.37 \\
3 & 3-nitropyridine & 1.39 & 0.30 & 1.47 & 1.01 & 0.71 \\
4 & 3-hydroxypyridine & 2.68 & 0.71 & 2.44 & 1.93 & 0.13 \\
5 & 3-aminopyridine & 3.30 & 0.82 & 2.74 & 2.20 & -0.09 \\
6 & 3-trifluoromethylpyridine & 1.65 & 0.52 & 1.97 & 1.50 & 0.46 \\
7 & 3-pyridinecarbonitrile & 1.49 & 0.43 & 1.79 & 1.33 & 0.62 \\
8 & 3-methylpyridine & 2.33 & 0.71 & 2.37 & 1.91 & -0.06 \\
9 & 3-methoxypyridine & 2.86 & 0.76 & 2.56 & 2.05 & 0.10 \\
10 & 3-acetylpyridine & 2.17 & 0.44 & 1.89 & 1.38 & 0.36 \\
11 & 3-tert-butylpyridine & 2.43 & 0.74 & 2.43 & 1.97 & -0.09 \\
12 & Nicotinic acid & 1.89 & 0.45 & 1.88 & 1.39 & 0.35 \\
\hline
\end{tabular}




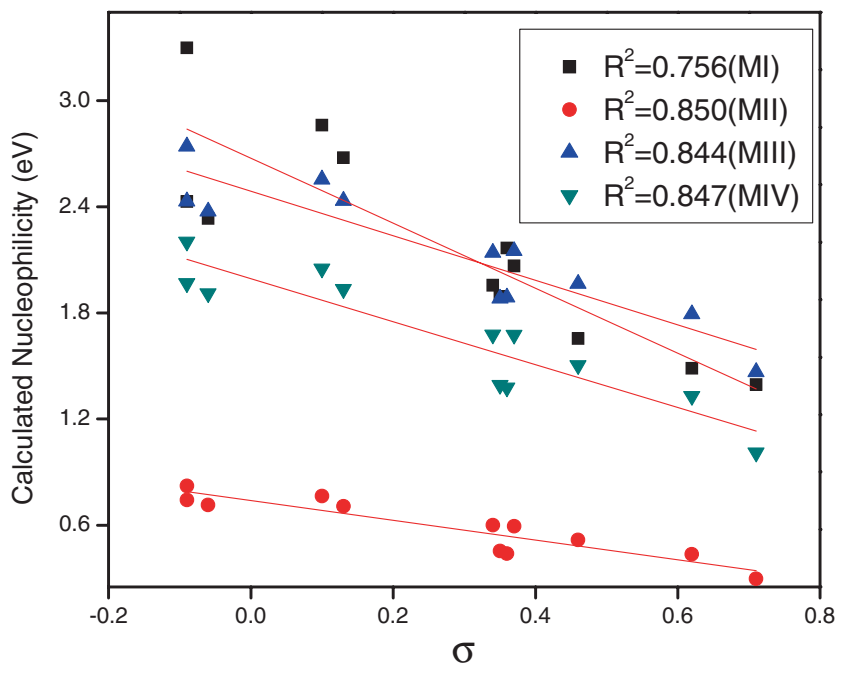

Figure 5. Gas phase nucleophilicity vs. Hammett substituent constant $(\sigma)$ for 3 -substituted pyridines. and IV. The analysis further confirms the negative impact of electron withdrawing substituent by placing 4-thionitrosopyridine and 4-nitropyridine at the bottom and second from the bottom of the scale respectively. Encouraged by the positive correlation of our analysis with the experimental results for 4-substituted pyridines, we intended to extend our study for 3substituted pyridines. However, no experimental data was found in the literature regarding the nucleophilicity value of 3-substituted pyridines. Accordingly, twelve 3 -substituted pyridines having known values of Hammett substituent constant, ${ }^{53}$ were considered for the determination of the gas phase global nucleophilicity. A comparative assessment of the nucleophilicities of 3 -substituted pyridines using all the four methods and their Hammett substituent constant $(\sigma)$ is summarized in table 4.

Table 5. Gas phase global nucleophilicity values (eV) of 32 commonly used 3-substituted pyridines calculated by methods II and IV.

\begin{tabular}{lcc}
\hline Compound & $\mathrm{N}^{\prime}$ & $\mathrm{N}^{\prime \prime \prime}$ \\
\hline 3-bromopyridine & 0.59 & 1.69 \\
Nicotamide & 0.52 & 1.54 \\
3-ethylpyridine & 0.73 & 1.94 \\
trans-3-(3-pyridyl)acrylic acid & 0.38 & 1.25 \\
3-pyridylacetonitrile & 0.59 & 1.65 \\
3-pyridylacetic acid & 0.67 & 1.83 \\
3-thionitrosopyridine & 0.16 & 0.65 \\
N-boc-3-aminomethylpyridine & 0.69 & 1.87 \\
Nicotinic hydrazide & 0.51 & 1.51 \\
Nicotinanilide & 0.53 & 1.61 \\
N,N-diethylnicotinamide & 0.64 & 1.80 \\
Methyl nicotinate & 0.49 & 1.47 \\
Ethyl 3-pyridylacetate & 0.69 & 1.87 \\
1-(pyridin-3-ylmethyl)piperidine-3-carboxylic acid & 0.78 & 2.11 \\
3-(pyrrol-1-ylmethyl)pyridine & 0.72 & 2.04 \\
3-(5-piperidin-4-yl-1,2,4-oxadiazol-3-yl)pyridine & 0.53 & 1.61 \\
3-pyridinepropanol & 0.72 & 1.92 \\
Ethyl nicotinate & 0.50 & 1.49 \\
Benzyl nicotinate & 0.50 & 1.50 \\
3-pyridinemethanol & 0.72 & 1.94 \\
3-pyridinealdoxime & 0.51 & 1.56 \\
3-picolylamine & 0.76 & 2.02 \\
3-ethynylpyridine & 0.56 & 1.65 \\
3-butylpyridine & 0.74 & 1.95 \\
3-benzoylpyridine & 0.41 & 1.33 \\
3-acetoxypyridine & 0.66 & 1.80 \\
3-(boc-amino)pyridine & 0.75 & 2.04 \\
3-pyridylpropanoic acid & 0.67 & 1.82 \\
3-isopropylpyridine & 0.73 & 1.94 \\
N,N-dimethyl-3-aminopyridine & 0.94 & 2.47 \\
(N,N-diethyl)-3-aminomethylpyridine & 0.81 & 2.19 \\
3-(pyrrolidino)pyridine & 0.99 & 2.59 \\
\hline & & \\
\hline
\end{tabular}


The calculated gas phase global nucleophilicity values were plotted against the Hammett substituent constant (figure 5). The regression coefficients for Methods I, II, III and IV were found to be 0.756 , $0.850,0.844$ and 0.847 , respectively. These methods could produce a moderate correlation of theoretical nucleophilicity trend of 3-substituted pyridines with respective Hammett substituent constants.

From the regression coefficient values (figure 5), it can be seen that Method II, III and IV produced similar results for 3-substituted pyridines, whereas method I showed somewhat poor correlation. Hence, methods II and IV, which produced the best fit, were considered for subsequent determination of nucleophilicity values of additional 32 commonly used 3-substituted pyridines. Results for the global nucleophilicity values are illustrated in table 5 .

Finally, a total of 443 -substituted pyridines were evaluated and a nucleophilicity scale has been constructed based on the results obtained from methods
II and IV (figure 6). From this scale, it was found that 3-pyrrolidino pyridine has the the highest and 3-thionitrosopyridine has the lowest nucleophilicity value.

Mayr et al. ${ }^{26}$ recently synthesized highly nucleophilic 3,4,5-triamino-substituted pyridine and determined their nucleophilicity in acetonitrile solution. We therefore made an attempt to substantiate the best theoretical model for prediction of nucleophilicity for 3,4,5-substituted pyridines reported by Mayr. ${ }^{26}$ The global nucleophilicity values are determined by gas phase calculation of HOMO-LUMO energy of the corresponding Mayr's 3,4,5-triamino-substituted pyridines. The results obtained using all the four methods are summarized in table 6.

The calculated global nucleophilicity values were plotted against the Mayr's experimental nucleophilicity values (figure 7).

The regression coefficient $\mathrm{R}^{2}$ values were found to be $0.791,0.743,0.822$ and 0.793 for method I, II, III and IV, respectively. From the regression coefficient

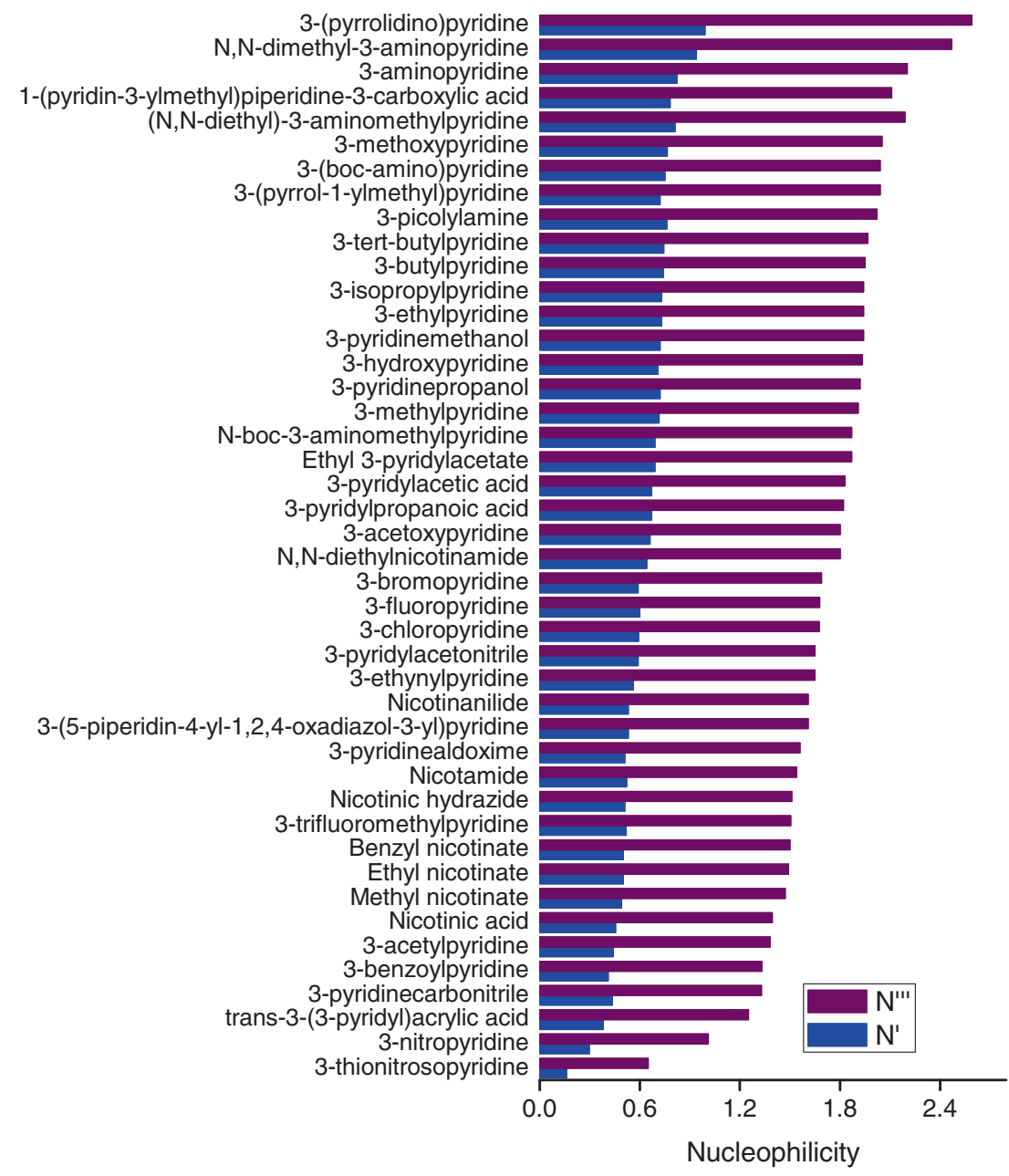

Figure 6. Nucleophilicity scale of 44 no. of 3-substituted pyridines based on gas phase calculation. 
Table 6. Calculated gas and solvent phase global nucleophilicity $(\mathrm{eV})$ and experimental values of Mayr's 3,4,5-substituted pyridine.

\begin{tabular}{|c|c|c|c|c|c|c|c|c|c|c|c|}
\hline \multirow[b]{2}{*}{ Entry } & \multirow{2}{*}{\multicolumn{2}{|c|}{ Compound }} & \multicolumn{2}{|c|}{$\mathrm{N}$} & \multicolumn{2}{|c|}{$\mathrm{N}^{\prime}$} & \multicolumn{2}{|c|}{$\mathrm{N}^{\prime \prime}$} & \multicolumn{2}{|c|}{$\mathrm{N}^{\prime \prime \prime}$} & \multirow[b]{2}{*}{ N Expt. ${ }^{2}$} \\
\hline & & & Gas & Solvent & Gas & Solvent & Gas & Solvent & Gas & Solvent & \\
\hline 1 & $\mathrm{M}-2 \mathrm{Bn}$ & & 4.43 & 3.95 & 1.11 & 1.06 & 3.50 & 3.40 & 2.87 & 2.78 & 17.69 \\
\hline 2 & $\mathrm{M}-2 \mathrm{Et}$ & & 4.39 & 3.78 & 1.29 & 1.17 & 3.67 & 3.46 & 3.12 & 2.90 & 16.81 \\
\hline 3 & $\mathrm{M}-2 \mathrm{Me}$ & & 4.31 & 3.88 & 1.27 & 1.20 & 3.62 & 3.53 & 3.08 & 2.97 & 16.65 \\
\hline 4 & $\mathrm{M}-2 \mathrm{Ac}$ & & 3.32 & 3.05 & 0.78 & 0.79 & 2.69 & 2.74 & 2.14 & 2.17 & 15.39 \\
\hline 5 & $\mathrm{M}-2 \mathrm{Bz}$ & & 3.46 & 3.14 & 0.61 & 0.59 & 2.45 & 2.43 & 1.83 & 1.81 & 14.19 \\
\hline
\end{tabular}

${ }^{\mathrm{a}}$ Experimental values are taken from the literature ${ }^{26}$; Solvent=acetonitrile.

$\left(\mathrm{R}^{2}\right)$ analysis it was found that Method III gave the best fit compared to the other three methods. The linearity relation values were not decent for all the four methods compared to those obtained for 4-substituted pyridines. To check whether inclusion of solvent model in the calculation has any effect on linearity relation or not, the solvent phase global nucleophilicity of

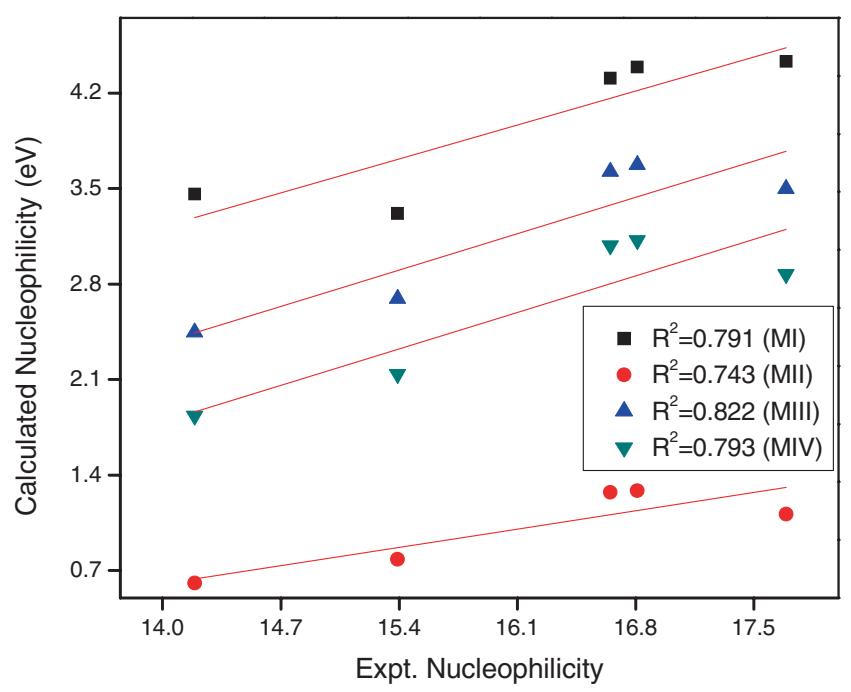

Figure 7. Gas phase Nucleophilicity vs. Expt. Nucleophilicity for 3,4,5-substituted pyridines.
Mayr's 3,4,5-triamino-substituted pyridines were calculated. For the solvent phase calculation of nucleophilicity, acetonitrile was used as solvent and the IEFPCM as a model. Applying the four methods of calculation, the nucleophilicity values were tabulated (table 6).

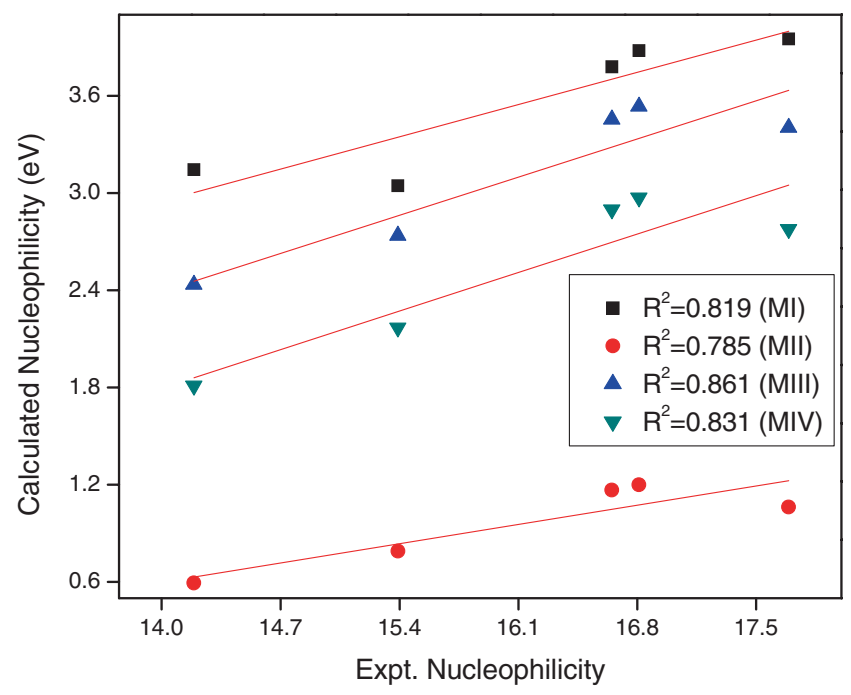

Figure 8. Calculated Nucleophilicity in IEFPCM solvent model vs Experimental Nucleophilicity for 3,4,5-substituted pyridines. 
A graphical representation of the results of the calculated solvent phase nucleophilicities against Mayr's experimental nucleophilicity values is shown in figure 8 . An interesting result came out of this study. As per experimental results, $\mathrm{M}-2 \mathrm{Bn}$ has the highest nucleophilicity value among all 5 experimentally synthesized pyridines. In our theoretical study, only method I is successful to predict the highest nucleophilicity value of $\mathrm{M}-2 \mathrm{Bn}$. But it is unsuccessful to predict the trend of nucleohilicity for M-2Ac and M-2Bz. Whereas method II, III and IV were able to predict the correct trend of nucleophilicity of M-2Me, M-2Et, M-2Ac and $\mathrm{M}-2 \mathrm{Bz}$, but particularly unsuccessful to predict the highest nucleophilicity value of M-2Bn.

In the solvent phase calculation, the regression coefficient $\left(\mathrm{R}^{2}\right)$ values were also analyzed. For all methods, it was found that the linearity relation value increases significantly. Method III generates the best fit for the solvent phase calculation also. The $\mathrm{R}^{2}$ value increases in this case for Method III from 0.822 to 0.861 . Therefore the gas phase global nucleophilicity for additional commonly available $263,4,5$-substituted pyridines were also determined by applying method III. The gas phase global nucleophilicity values, calculated by method III are listed in table 7.

A nucleophilicity scale has been constructed (figure 9) for 31 numbers of 3,4,5-substituted pyridines. From the scale we found that 3,5-dimethyl-4-aminopyridine has the highest nucleophilicity value among the 26 pyridines considered in table 7 .

\subsection{Construction of new molecules of 4-substituted pyridine}

Amongst the three categories of substituted pyridines considered in the present study, a good correlation of calculated values with experimental nucleophilicity values as well as Hammett substituent constant has been obtained only for 4-substituted pyridines. This study also supported by the experimental observation of superior nucleophilic character of 4-(pyrrolidino)pyridine,

Table 7. Gas phase global nucleophilicity values (eV) of 26 commonly available 3,4,5substituted pyridine calculated by Method III.

\begin{tabular}{lcc}
\hline Entry & Compound & $\mathrm{N}^{\prime \prime}$ \\
\hline 1 & 3,5-dichloro-4-pyridinecarbonitrile & 1.58 \\
2 & 3,5-dichloro-4-pyridinecarboxaldehyde & 1.53 \\
3 & 3,5-dichloropyridine-4-carboxylic acid & 1.91 \\
4 & 3,5-difluoro-4-formylpyridine & 1.53 \\
5 & 3,5-difluoropyridine-4-carboxylic acid & 1.69 \\
6 & 3.5-dimethyl-4-aminopyridine & 2.98 \\
7 & Methyl 3,5-dichloropyridine-4-carboxylate & 1.96 \\
8 & 1-(3,5-dichloropyridin-4-yl)piperazine & 2.48 \\
9 & 3,4,5-trichloropyridine & 1.96 \\
10 & 3,5-dibromo-4-pyridinecarboxaldehyde & 1.54 \\
11 & 3-amino-4-chloro-5-methoxypyridine & 2.59 \\
12 & 3,5-dichloro-4-methylpyridine & 2.13 \\
13 & 4-bromo-3-chloro-5-nitropyridine & 1.43 \\
14 & 4-amino-3-bromo-5-chloropyridine & 2.43 \\
15 & 4-bromo-3,5-dichloropyridine & 1.95 \\
16 & 3-bromo-5-hydroxy-4-pyridinecarboxylic acid & 1.73 \\
17 & 3,4-dichloro-5-pyridinecarboxylic acid & 1.73 \\
18 & 4-amino-5-methyl-3-nitropyridine & 1.65 \\
19 & 5-chloro-3,4-diaminopyridine & 2.82 \\
20 & 5-bromo-3,4-diaminopyridine & 2.81 \\
21 & 3-bromo-5-methyl-4-nitropyridine & 1.53 \\
22 & 3-amino-5-methoxyisonicotinonitrile & 2.15 \\
23 & 4-amino-3,5-dichloropyridine & 2.43 \\
24 & 4-amino-5-bromo-3-methylpyridine & 2.70 \\
25 & 3,5-dichloro-4-nitropyridine & 1.50 \\
26 & 3-chloro-5-hydroxy-4-pyridinecarboxylic acid & 1.73 \\
\hline & &
\end{tabular}




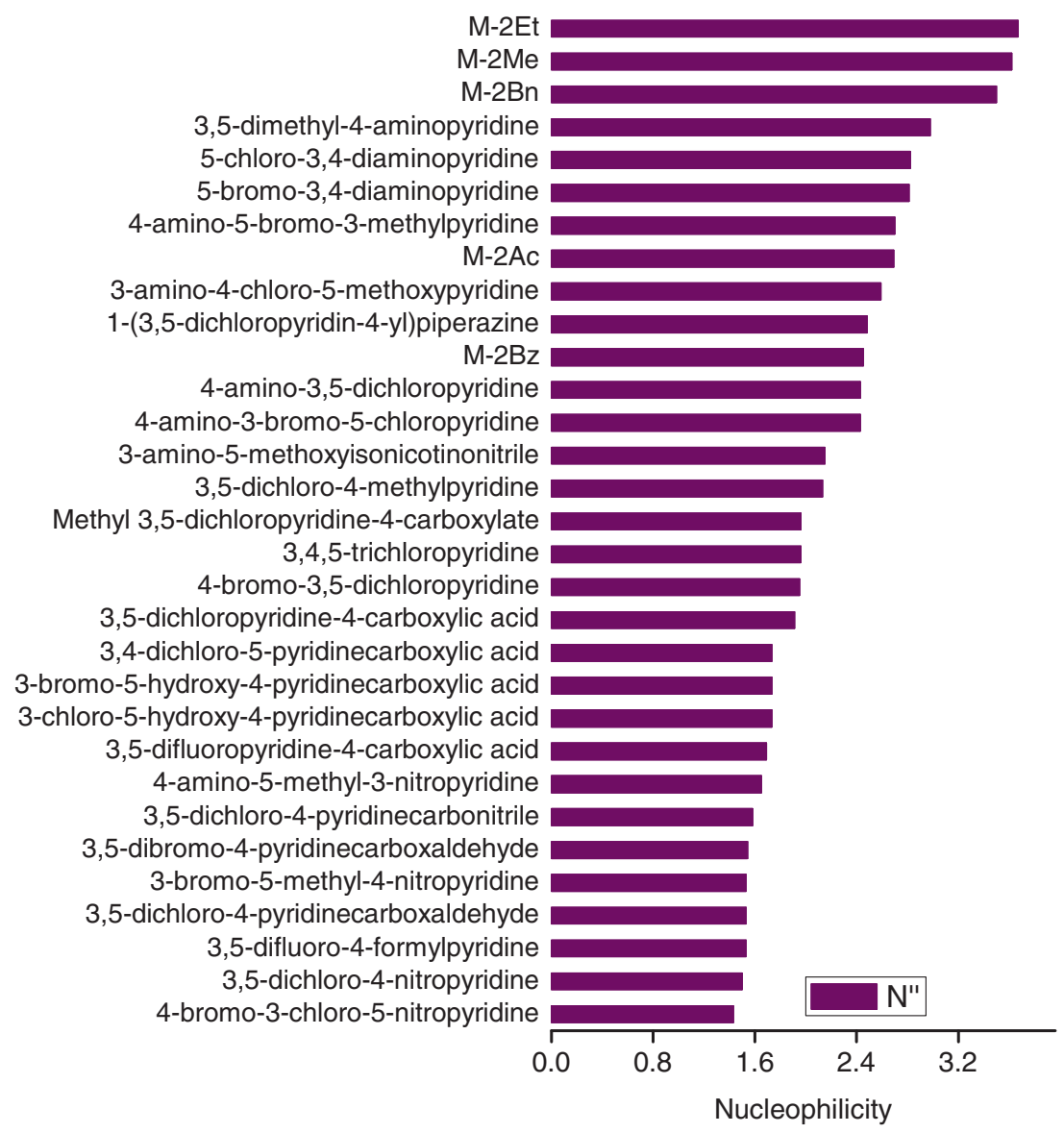

Figure 9. Nucleophilicity scale of 31 no. of 3,4,5-substituted pyridine based on gas phase calculation.

$\mathbf{T}_{\mathbf{1}}$. However, it is highly desirable to construct pyridines having better nucleophilic property than $\mathbf{T}_{\mathbf{1}}$. Hence, a total of 30 new 4-(N,N-disubstituted)pyridines having structural similarity with $\mathbf{T}_{\mathbf{1}}$ have been proposed. To find out the best choice out of all these proposed pyridines, nucleophilicity values were computed using method IV. Method IV has been chosen because it gives good correlation value for experimental as well as Hammett substitution constant $(\sigma)$ for 4-substituted pyridines. Furthermore, method IV is particularly consistent in predicting nucleophilicity trends among all categories of pyridines studied here. The nucleophilicity values calculated for newly proposed molecules obtained by using method IV are summarized in table 8 .

It can be seen from table 8 that six molecules show better nucleophilic behavior than pyridine $\mathbf{T}_{\mathbf{1}}$. Analysis of the results revealed that the nucleophilicity value decreases on expansion of the ring size (table 8 , molecules $\mathbf{T}_{\mathbf{2}}$ and $\mathbf{T}_{\mathbf{1 1}}$ ). A similar trend was observed when molecules are proposed with decreasing ring size (table 8, molecules $\mathbf{T}_{\mathbf{8}}$ and $\mathbf{T}_{\mathbf{9}}$ ). Nucleophilicity of $\mathbf{T}_{\mathbf{2}}$ decreases on substitution of dimethyl group in 2 and 6 position of the piperidine ring (table 8 , molecule $\mathbf{T}_{31}$ ). But, nucleophilicity of $\mathbf{T}_{\mathbf{1 1}}$ could be enhanced significantly by substituting - $\left(\mathrm{CH}_{2}\right)_{\mathrm{n}}$-group in 2 and 6 position of azepane ring, where $n=3,4$ (table 8 , molecules $\mathbf{T}_{28}$ and $\mathbf{T}_{\mathbf{2 9}}$ ). Substitution of dimethyl amino group in 2 and 5 position of the pyrrolidine ring (table 8, molecule $\mathbf{T}_{\mathbf{1 3}}$ ) decreases nucleophilicity. Methyl and dimethyl substituent in 2 and 5 position of the pyrrolidine ring (table 8, molecules $\mathbf{T}_{\mathbf{2 0}}$ and $\mathbf{T}_{\mathbf{2 7}}$ ) increases the nucleophilicity. Substitution by $-\left(\mathrm{CH}_{2}\right)_{\mathrm{n}}$ - increases the nucleophilicity for $n=4$ (molecule $\mathbf{T}_{\mathbf{2 6}}$ ) but decreases the nucleophilicity for $\mathrm{n}=2$ and 3 (table 8 , molecules $\mathbf{T}_{19}$ and $\mathbf{T}_{\mathbf{3 0}}$ ). Substitution of piperazine at 4-position of the pyridine ring does not increase the nucleophilicity of the pyridine ring (molecule $\mathbf{T}_{\mathbf{1 0}}$ ). The nucleophilicity of $T_{10}$ compared to $T_{1}$ can be enhanced by substitution, particularly for molecule $\mathbf{T}_{\mathbf{2 4}}$. Other substituent does not increase the nucleophilicity of $\mathbf{T}_{\mathbf{1 0}}$ (molecules $\mathbf{T}_{7}, \mathbf{T}_{17}, \mathbf{T}_{22}, \mathbf{T}_{23}$ and $\mathbf{T}_{25}$ ). A comparative evaluation of newly designed 4-( $N, N$-disubstituted)pyridines having nucleophilic profile better than $\mathbf{T}_{1}$ have been illustrated in figure 10. 
Table 8. Gas phase global nucleophilicity values of constructed pyridine molecule based on Method IV.

\begin{tabular}{|c|c|c|c|c|c|c|c|}
\hline No. & Compound & $\mathrm{E}_{\text {HOMO }}(\mathrm{au})$ & $\mathrm{E}_{\mathrm{LUMO}}(\mathrm{au})$ & $\eta(\mathrm{eV})$ & $\mu(\mathrm{eV})$ & $\omega^{-}(\mathrm{eV})$ & $\mathrm{N}^{\prime \prime \prime}(\mathrm{eV})$ \\
\hline $\mathbf{T}_{1}$ & & -0.21411 & -0.01287 & 5.47602 & 3.088221 & 3.627974 & 2.756 \\
\hline $\mathbf{T}_{2}$ & & -0.22105 & -0.02077 & 5.449897 & 3.290129 & 3.97195 & 2.518 \\
\hline $\mathbf{T}_{\mathbf{3}}$ & & -0.21170 & -0.01540 & 5.341596 & 3.089853 & 3.666106 & 2.728 \\
\hline $\mathbf{T}_{4}$ & & -0.21826 & -0.01755 & 5.461598 & 3.208359 & 3.830246 & 2.611 \\
\hline $\mathbf{T}_{5}$ & & -0.21191 & -0.01871 & 5.257241 & 3.137745 & 3.77019 & 2.652 \\
\hline$T_{6}$ & & -0.21435 & -0.01772 & 5.350576 & 3.157474 & 3.776431 & 2.648 \\
\hline $\mathbf{T}_{7}$ & & -0.21454 & -0.01763 & 5.358195 & 3.158834 & 3.776542 & 2.648 \\
\hline $\mathbf{T}_{8}$ & & -0.24206 & -0.02923 & 5.7914 & 3.691089 & 4.559984 & 2.193 \\
\hline $\mathbf{T}_{9}$ & & -0.22099 & -0.01574 & 5.585138 & 3.220876 & 3.816947 & 2.620 \\
\hline $\mathbf{T}_{10}$ & & -0.21701 & -0.01708 & 5.440373 & 3.184957 & 3.797071 & 2.634 \\
\hline $\mathbf{T}_{11}$ & & -0.21471 & -0.01529 & 5.426495 & 3.12931 & 3.708397 & 2.697 \\
\hline $\mathbf{T}_{12}$ & & -0.23061 & -0.02335 & 5.639833 & 3.455302 & 4.197068 & 2.383 \\
\hline $\mathbf{T}_{13}$ & & -0.21591 & -0.01345 & 5.509218 & 3.120602 & 3.672239 & 2.723 \\
\hline $\mathbf{T}_{14}$ & & -0.22328 & -0.01608 & 5.6382 & 3.256659 & 3.861784 & 2.589 \\
\hline $\mathbf{T}_{15}$ & & -0.21524 & -0.01467 & 5.457788 & 3.128085 & 3.69799 & 2.704 \\
\hline $\mathbf{T}_{16}$ & & -0.22013 & -0.01414 & 5.605274 & 3.187406 & 3.756532 & 2.662 \\
\hline $\mathbf{T}_{17}$ & & -0.21569 & -0.01431 & 5.47983 & 3.12931 & 3.694167 & 2.707 \\
\hline
\end{tabular}


Table 8. (continued)

\begin{tabular}{|c|c|c|c|c|c|c|c|}
\hline No. & Compound & $\mathrm{E}_{\text {Hомо }}(\mathrm{au})$ & $\mathrm{E}_{\text {LUMO }}(\mathrm{au})$ & $\eta(\mathrm{eV})$ & $\mu(\mathrm{eV})$ & $\omega^{-}(\mathrm{eV})$ & $\mathrm{N}^{\prime \prime \prime}(\mathrm{eV})$ \\
\hline $\mathbf{T}_{18}$ & & -0.21213 & -0.01455 & 5.376426 & 3.084139 & 3.647285 & 2.742 \\
\hline $\mathbf{T}_{19}$ & & -0.22310 & -0.01738 & 5.597927 & 3.271898 & 3.89819 & 2.565 \\
\hline $\mathbf{T}_{20}$ & & -0.21290 & -0.01236 & 5.456972 & 3.064819 & 3.594775 & 2.782 \\
\hline $\mathbf{T}_{21}$ & & -0.21724 & -0.03812 & 4.874104 & 3.47435 & 4.518387 & 2.213 \\
\hline $\mathbf{T}_{22}$ & & -0.21222 & -0.01707 & 5.310303 & 3.11965 & 3.724423 & 2.685 \\
\hline $\mathbf{T}_{23}$ & & -0.20459 & -0.01923 & 5.043903 & 3.045227 & 3.676395 & 2.720 \\
\hline $\mathbf{T}_{24}$ & & -0.20316 & -0.01745 & 5.053427 & 3.001552 & 3.599429 & 2.778 \\
\hline $\mathbf{T}_{25}$ & & -0.19820 & -0.03897 & 4.33287 & 3.226863 & 4.28741 & 2.332 \\
\hline $\mathbf{T}_{26}$ & & -0.21189 & -0.01357 & 5.396563 & 3.06754 & 3.614721 & 2.766 \\
\hline $\mathbf{T}_{27}$ & & -0.21176 & -0.01205 & 5.434387 & 3.045091 & 3.568473 & 2.802 \\
\hline $\mathbf{T}_{28}$ & & -0.21198 & -0.01337 & 5.404454 & 3.066043 & 3.610221 & 2.770 \\
\hline $\mathbf{T}_{29}$ & & -0.21159 & -0.01319 & 5.39874 & 3.058288 & 3.59903 & 2.779 \\
\hline $\mathbf{T}_{\mathbf{3 0}}$ & & -0.21497 & -0.01479 & 5.447176 & 3.126044 & 3.697456 & 2.705 \\
\hline $\mathbf{T}_{31}$ & & -0.21811 & -0.03825 & 4.894241 & 3.487956 & 4.535614 & 2.205 \\
\hline
\end{tabular}




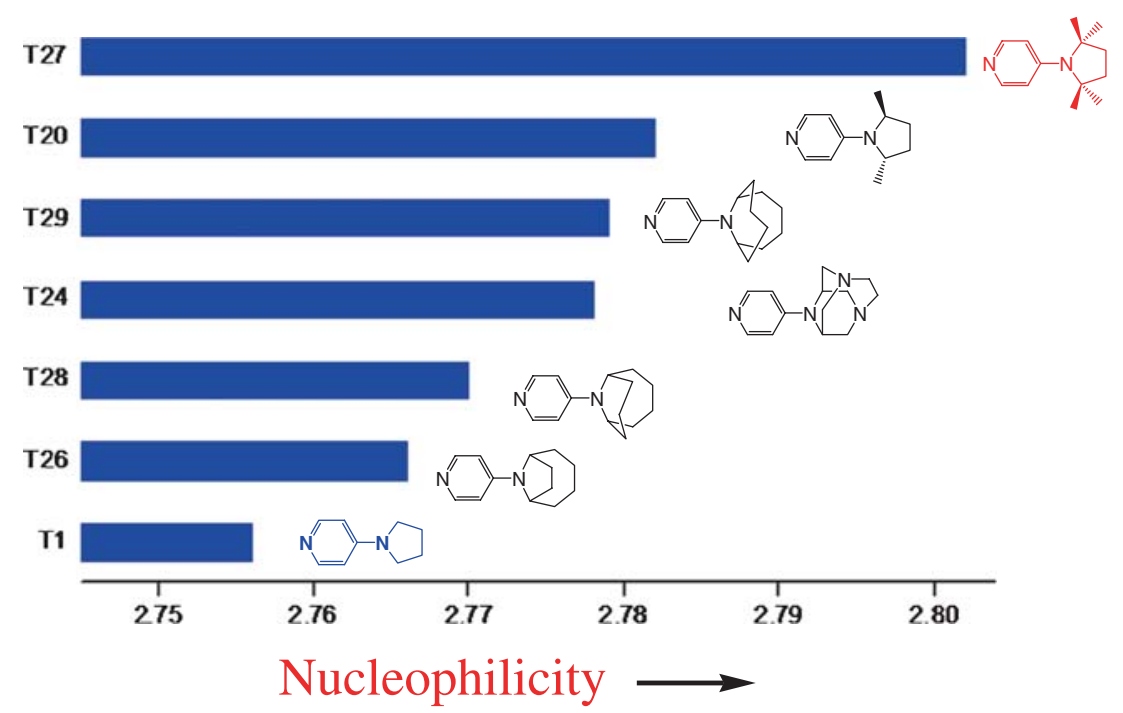

Figure 10. Nucleophilicity scale of the proposed molecules having nucleophilic profile better than $\mathbf{T}_{\mathbf{1}}$ based on Method IV.

\section{Conclusions}

A theoretical study has been carried out to correlate the nucleophilic behavior of altogether 125 commonly available 3-substituted pyridines, 4-substituted pyridines and 3,4,5-substituted pyridines. Initially, the goodness and linearity of all the four methods of the present study for 3-substituted, 4-substituted and 3,4,5-substituted pyridines were established. Amongst the three categories of pyridines, only 4-substituted pyridines show very good correlation with experimental as well as Hammett substituent constant. The predictive performance of all the four models were found to follow a declining trend when substitutions are present in 3-position of the pyridine ring. This may be due to the different electronic effect operating in the pyridine ring for meta-substitution. Gas phase calculation for 4-substituted pyridines show that method I gives poor $\mathrm{R}^{2}$ values with Hammett substituent constant, whereas $\mathrm{R}^{2}$ values are similar for all methods with Mayr's experimental values. Inclusion of solvent model increases the linearity between calculated and experimental values for 4-substituted and 3,4,5-substituted pyridines. With the help of this model 30 new 4-substituted pyridine molecules were constructed and the gas phase nucleophilicity values were evaluated. The nature of substitution and ring size of the substituent have great influence on the nucleophilicity of 4-substituted pyridines. On the basis of our study, molecules $\mathbf{T}_{\mathbf{2 0}}, \mathbf{T}_{\mathbf{2 4}}, \mathbf{T}_{\mathbf{2 6}}$, $\mathbf{T}_{27}, \mathbf{T}_{28}$ and $\mathbf{T}_{29}$ are found to be more nucleophilic in nature. These molecules deserve the experimental validation of nucleophilicity as well as effectiveness as organocatalyst.

\section{Supplementary Information (SI)}

Additional information pertaining to leave-one-out correlation and regression analysis by distribution of molecules into training and test sets is available in Supporting Information at www.ias.ac.in/chemsci.

\section{Acknowledgements}

Financial support from UGC (Grant No. 41-206/2012/ SR) is gratefully acknowledged.

\section{References}

1. Ramsay W 1876 Phil. Mag. 2269

2. Wu W, Kong H, Li H, Ho Y, Gao Y, Hao J, Murphy M B, Lam M H, Wong K and Lee C 2011 Eur. J. Org. Chem. 265054

3. Wu J, Kang S, Song B, Hu D, He M, Jin L and Yang S 2012 Chem. Central J. 628

4. Di X, Liu Y, Liu Y, Yu X, Xiao H, Tian X and Gao R 2007 Pesticide Biochem. Physiol. 8981

5. Dorn F, Pfiffner A and Schlageter M 1991 ACS Symposium Series $\mathbf{4 4 3} 506$

6. Lee L F, Stikes G L, Normansell J E, Molyneaux J M, Sing L Y L, Chupp J P, Parrish S K and Kaufmann J E 1991 ACS Symposium Series $\mathbf{4 4 3} 195$

7. Peine G, Hoffmann P, Seifert G and Schilling G 1985 Biochem. Physiol. Pflanzen 1801

8. Harris R L N, Huppatz J L, Phillips J N and Teitei T 1979 In Advances in Pesticide Science H Geissbühler, G T Brooks and P C Kearney (Eds.) (Oxford: Pergamon) p. 99

9. Willand-Charnley R, Fisher T J, Johnson B M and Dussault P H 2012 Org. Lett. 142242

10. Zhang Y, Zhang Y, Sun Y L, Du X, Shi J Y, Wang W D and Wang W 2012 Chem. Eur. J. 186328 
11. Ko K, Nakano K, Watanabe S, Ichikawa Y and Kotsuki H 2009 Tetrahedron Lett. 504025

12. Xu X, Tang Z, Wang Y, Luo S, Cun L and Gong L 2007 J. Org. Chem. 729905

13. List B 2007 Chem. Rev. 1075413

14. Cheong P H-Y, Legault C Y, Um J M, Cęlebi-Ołcu̧m N and Houk K N 2011 Chem. Rev. 1115042

15. De Rycke N, Couty F and David O R P 2011 Chem. Eur. J. 1712852

16. Geerlings P, De Proft F and Langenaeker W 2003 Chem. Rev. 1031793

17. Ingold C K 1934 Chem. Rev. 15225

18. Swain C G and Scott C B 1953 J. Am. Chem. Soc. 75 141

19. Edwards J O 1954 J. Am. Chem. Soc. 761540

20. Edwards J O and Pearson R G 1962 J. Am. Chem. Soc. 8416

21. Bunnett J F 1963 Ann. Rev. Phys. Chem. 14271

22. Pearson R G, Sobel H and Songstad J 1968 J. Am. Chem. Soc. 90319

23. Legon A C and Millen D J 1987 J. Am. Chem. Soc. 109 356

24. Legon A C and Millen D J 1987 Acc. Chem. Res. 2039

25. Brotzel F, Kempf B, Singer T, Zipse H and Mayr H 2007 Chem. Eur. J. 13336

26. De Rycke N, Berionni G, Couty F, Mayr H, Goumont R and David O R P 2011 Org. Lett. 13530

27. Campodonico P, Santos J G, Andres J and Contreras R 2004 J. Phys. Org. Chem. 17273

28. Contreras R, Andres J, Safont V S, Campodonico P and Santos J G 2003 J. Phys. Chem. A 1075588

29. Chattaraj P K and Maiti B 2001 J. Phys. Chem. A 105 169

30. Pratihar S and Roy S 2010 J. Org. Chem. 754957

31. Pratihar S and Roy S 2011 Organometallics 303257

32. Domingo L R and Pérez P 2011 Org. Biomol. Chem. 9 7168

33. Campodónico P R and Aizman A 2006 Chem. Phys. Lett. 422204

34. Deuri S and Phukan P 2012 Comput. Theor. Chem. 980 49

35. Soliman S M 2012 Comput. Theor. Chem. 994105

36. Ess D H, Jones G O and Houk K N 2006 Adv. Synth. Catal. 3482337
37. Chattaraj P K, Sarkar U and Roy D R 2006 Chem. Rev. 1062065

38. Chattaraj P K and Roy D R 2007 Chem. Rev. 107 PR46

39. Chattaraj P K, Giri S and Duley S 2011 Chem. Rev. 111 PR43

40. Parr R G and Pearson R G 1983 J. Am. Chem. Soc. 105 7512

41. Parr R G, Von Szentpaly L and Liu S 1999 J. Am. Chem. Soc. 1211922

42. Parr R G, Donnelly R A, Levy M and Palke W E 1978 J. Chem. Phys. 683801

43. Gázquez J L, Cedillo A and Vela A 2007 J. Phys. Chem. A 1111966

44. Domingo L R, Chamorro E and Perez P 2008 J. Org. Chem. 734615

45. Kohn W and Sham L J 1965 Phys. Rev. 1401133

46. Becke A D 1993 J. Chem. Phys. 985648

47. Lee C, Yang W and Parr R G 1988 Phys. Rev. B 37785

48. Cohen A, Mori-Sánchez P and Yang W 2012 Chem. Rev. 112289

49. Frisch M J, Trucks G W, Schlegel H B, Scuseria G E, Robb M A, Cheeseman J R, Zakrzewski V G, Montgomery J A, Stratmann R E, Burant J C, Dapprich S, Millam J M, Daniels A D, Kudin K N, Strain M C, Farkas O, Tomasi J, Barone V, Cossi M, Cammi R, Mennucci B, Pomelli C, Adamo C, Clifford S, Ochterski J, Petersson G A, Ayala P Y, Cui Q, Morokuma K, Malick D K, Rabuck A D, Raghavachari K, Foresman J B, Cioslowski J, Ortiz J V, Baboul A G, Stefanov B B, Liu G, Liashenko A, Piskorz P, Komaromi I, Gomperts R, Martin R L, Fox D J, Keith T, Al- Laham M A, Peng C Y, Nanayakkara A, Gonzalez C, Challacombe M, Gill P M W, Johnson B, Chen W, Wong M W, Andres J L, Gonzalez C, Head Gordon M, Replogle E S and Pople J A 2004 GAUSSIAN 03, Revision E.01, (Gaussian Inc.: Wallingford, CT)

50. Swain C G, Swain M S, Powell A L and Alunni S 1983 J. Am. Chem. Soc. 105502

51. Um I-H, Lee E-J and Jeon S-E 2002 J. Phys. Org. Chem. 15561

52. Kim Y, Cramer C J and Truhlar D G 2009 J. Phys. Chem. A 1139109

53. Smith M B and March J 2007 In Advanced Organic Chemistry: Reactions, Mechanism and Structure $6^{\text {th }}$ edn., (Hoboken- New Jersey: John Wiley) 